\title{
INVESTIGATION ON PHARMACOGNOSY AS WELL AS THE ANTIOXIDANT, ANTI-INFLAMMATORY POTENTIAL OF THE KATHA POWDER
}

\author{
PANKAJ SHARMA*, RAJU L \\ Department of Pharmacy, Government Pharmacy College Seraj, Mandi, Himachal Pradesh, India. \\ Email: pankajsharmadrugs@gmail.com
}

Received: 06 April 2021, Revised and Accepted: 05 May 2021

\begin{abstract}
Objective: The objective of the study was to investigate the pharmacognosy as well as the antioxidant, anti-inflammatory potential of the Katha powder.

Methods: The Coarsely dried chips of Acacia catechu heartwood were treated with $10 \%$ hydro-alcoholic solution to obtain Katha as the final product. The powdered Katha was standardized through pharmacognostic parameters. This Katha power is showing the good solubility in the hot water having astringent in the taste. The powder microscopy of the Katha powder is to be demonstrated fragments of acicular crystals, fibers, and bordered pitted vessels. Katha powder antioxidant potential is to be accessed by using the 2, 2-diphenyl-1-picryl hydrazyl assay and NO Scavenging assay using ascorbic acid as a standard drug. Further, the Katha powder is to be subjected for the assessment of its anti-inflammatory potential by the use of heatinduced hemolysis as well as hypotonicity-induced hemolysis approach by the use of the aspirin or diclofenac sodium as a standard drug.
\end{abstract}

Results: Microscopical investigations were showed that Katha showing the presence of fragments of acicular crystals, fibers, and bordered pitted vessels. In vitro study shows that the Katha powder has excellent antioxidant as well as anti-inflammatory potential in a dose-dependent manner in comparison of the result of heartwood of $A$. catechu.

Conclusion: So from this investigation, it is to be suggested that the Katha powder is rich in the phenolic compound and the experimentation study shows that the drug is to possess a good antioxidant as well as anti-inflammatory property.

Keywords: Acacia catechu, Polyphenolics, Katha, 2, 2-diphenyl-1-picryl hydrazyl, Nitric oxide.

(C) 2021 The Authors. Published by Innovare Academic Sciences Pvt Ltd. This is an open access article under the CC BY license (http://creativecommons.org/ licenses/by/4.0/) DOI: http://dx.doi.org/10.22159/ajpcr.2021v14i6.41710. Journal homepage: https://innovareacademics.in/journals/index.php/ajpcr

\section{INTRODUCTION}

Acacia catechu heartwood is to be used in the preparation of a potent medicinal product is known as a Katha [1]. Katha is a brown color chocolate fracture hard with characteristics odor and having the astringent in taste. Katha having good hot water solubility and insoluble in cold water. Katha is rich in Catechin, its content in the powder is varies from 20 to $25 \%$ in Katha powder [2]. This Katha having a strong astringent taste due to the high content of tannin as an active compound. Katha content from the heartwood is to be enhanced by the extraction with the $10 \%$ hydroalcoholic solution instead of using the aqueous solution. Resultantly, the yield value of the Katha increases more than the traditional approach used in the extraction of the Katha. Some research has been reported that the Katha powder is showing various pharmacological actions such as antioxidant, antibacterial, anti-inflammatory, wound healing, and astringent action [3]. Katha is to be having more wound healing activity for diabetic patients whose wound is to be healing very slowly [4]. Moreover, the chemical examination manifests that Katha accommodates some of the phenolic components, especially catechin/epicatechin, quercetin, taxifolin and that is suggested to possess an antioxidant, anti-inflammatory, astringent, and antidiabetic outcome [5]. Hence, the present study is to design to access the in vitro antioxidant, anti-inflammatory potential of the Katha powder by used a specific approach for its estimation.

\section{METHODS}

\section{Plant material}

The heartwood of the plant was collected in November 2019 from Solandistrict of Himachal Pradesh, India, which further was authenticated by Raw material herbarium and museum, NISCAIR, New Delhi, India.
A voucher specimen of the plant was preserved in the herbarium for reference (NISCAIR/RHHD/Consult/2019/3465-66).

\section{Preparation of Katha}

The heartwood of the young mature plant of $A$. catechu was dried at room temperature $\left(25 \pm 2^{\circ} \mathrm{C}\right)$ for 4 consecutive weeks and pulverized [6]. Katha was obtained from the heartwood of $A$. catech $u$ by boiling the chips of heartwood with a $10 \%$ hydro-alcoholic solution. Trees of elevated girth having white lines on them are favored. Afresh felled trees further accord higher yields subsequently dried ones. Dead/Inferior trees are not utilized for extraction operation. This finally concentrated material receives crystallized, over the cooling process [7]. Concentrated material was kept for 2 days in the refrigerator at the temperature of $8^{\circ} \mathrm{C}$. The crystallized material was then filtered below the negative pressure to withdraw the last fragment of mother liquor sticking to the residue. The residue was cleaned with $15 \mathrm{ml}$ of ice-cold water and it was dried under vacuum to a constant weight. The rectangular shape chips are cut into a biscuit-like shape, termed as Katha. Katha is dried inside the drying chamber for 16-22 days with the cold air. The moisture pills down inside this chamber. It is the final platform of extraction of Katha. This chamber containing the hot air that accustomed the Katha. Following, the ambient drying, it obtained accessible for the packing operation. The steps involved in Katha processing are to be described below in Fig. 1.

\section{Pharmacognostical evaluation of Katha} Organoleptic evaluation

The organoleptic characters are the various sensory parameters of $A$. catechu (Katha) such as shape and size; color, odor, taste, and fracture of Katha were resolution. It encompasses inferences drench from examination ensued due to impressions on organs of senses [8]. 
The percent yield of Katha after extraction

To estimate the percent yield of Katha the heartwood of A. catechu (Katha) is to be extracted with $10 \%$ of hydroalcoholic hot distilled water. After achievement of extraction, a concentrated liquid is obtained is kept for 2 days in a refrigerator at the temperature of $8^{\circ} \mathrm{C}$. In this period Katha is to be get crystallized. The final crystallized material is to be obtained is to be known as a Katha [9].

The percentage of Katha was determined as:

Weight of chips taken for extraction $=\mathrm{X} g$

Weight of Katha obtained $=$ Y g

$\%$ Yield Kath

a percentage $=\frac{Y}{X} \times 100$

Histochemical studies and powder microscopy

These inspections were accomplished to realize the inclusions and comprehensive anatomical aspects of the botanical drug (Katha).

\section{Fluorescence behavior of the Katha powder}

Fluorescence behavior concerning botanical drug Katha powder below ordinary light or UV light (UV $366 \mathrm{~nm}$ ) is to be resolute, consequently, the powder of Katha sample and with different chemical the visibility of changeable colors that are mentioned in the tabulated form in result portion [10]. When physio-chemical boundaries are insufficient as they frequently take place among the Katha as powdered drugs, the botanical material is conceivably recognized since inherent adulterants/ impurities following the fluorescence inspection. Nature of A. catechu (Katha) powder among distinct chemical reagents was executed to disclose the phenomenon of phytoconstituents accompanying color changes below ordinary day-light through special technique [11].

\section{Antioxidant potential of the Katha powder}

Antioxidant activities assay by 2, 2-diphenyl-1-picryl hydrazyl (DPPH) The DPPH radical scavenging potential assessment elucidated was pursued with slight alterations. The $\mathrm{H}$ atom or electron contributing capacity of the Katha powder was estimated against the development of the purple-colored methanol solution of DPPH. This spectrophotometric assay utilized the stable radical, DPPH, as a testing agent. The working solutions of the extracts produced in methanol and distinct concentrations of Katha powder were utilized. Ascorbic acid was utilized as standard in $0.2-1.0 \mathrm{mg} / \mathrm{ml}$ solution. DPPH $(0.002 \%)$ was processed in methanol and $1 \mathrm{ml}$ of DPPH solution; $1 \mathrm{ml}$ of sample Katha powder in solution was added. The solution mixture was supported in dark for $30 \mathrm{~min}$ and absorbance was estimated at $517 \mathrm{~nm}$. DPPH solution of $1 \mathrm{ml}$ was utilized as blank [12]. The absorbance was listed and inhibition was deliberated by utilizing the formula designated below.

$$
\begin{aligned}
&(\text { Absorbance of thecontrol })- \\
& \text { DPPH scavenging activity }(\%)=\frac{(\text { Absorbanceof thesample })}{\text { Theabsorbance of thecontrol }} \times 100
\end{aligned}
$$

Nitric oxide (NO) scavenging technique

NO radical scavenging potential of the specimen can be executed by utilizing Griess [13]. $75 \mu \mathrm{l}$ of different concentrations of Katha powder is incubated with $75 \mu$ l sodium nitroprusside under visible light polychromatic light for $60 \mathrm{~min}$ in a 96 - well microplate. For control, $75 \mu \mathrm{l} 95 \%$ methanol is added in place of samples. $150 \mu \mathrm{l}$ Griess reagent is then append to the reaction mixture and absorbance is recorded spectrophotometrically around $550 \mathrm{~nm}$ [14]. Percent NO Scavenging was determined by utilizing the subsequent equation:

$$
\begin{gathered}
(\text { Absorbance of thecontrol })- \\
\text { NO scavenging activity }(\%)=\frac{(\text { Absorbance of the sample })}{\text { Theabsorbance of thecontrol }} \times 100
\end{gathered}
$$

\section{Anti-inflammatory potential of the Katha powder}

The blood was possessed from normal human volunteer those which has not confiscated any NSAIDs which is stand (nonsteroidal and antiinflammatory medicine) for 2 weeks preceding the investigation and transmitted to the centrifuge tubes. The tubes were separated at very high-speed rotation at $3000 \mathrm{rpm}$ for $10 \mathrm{~min}$ and were cleaned 3 times with equal volume of normal saline. The volume of blood was estimated and regenerate as $10 \% \mathrm{v} / \mathrm{v}$ suspension with normal saline [15].

Heat-induced hemolysis

Reaction mixture $2 \mathrm{ml}$ was appraised of $1 \mathrm{ml}$-test Katha powder (100$500 \mu \mathrm{g} / \mathrm{ml}$ ) and $1 \mathrm{ml}$ of $10 \%$ RBCs suspension; alternatively, the test sample at most saline was attached to the control test tube. Aspirin was utilized as a standard drug for comparison of anti-inflammatory activity. Entire centrifuge tubes accommodated reaction mixture were incubated interior the water bath at $56^{\circ} \mathrm{C}$ for $30 \mathrm{~min}$. Finally, of the incubation, the tubes were cooled below the water tap. The reaction mixture was separated by rotating at a high speed of $2500 \mathrm{rpm}$ for a time of $5 \mathrm{~min}$ and the absorbance of the supernatants were confiscate at $560 \mathrm{~nm}$. The investigation was executed 3 times for the entire specimen [16]. The \% inhibition of hemolysis was deliberated in such a way:

$$
\begin{gathered}
(\text { Absorbanceof thecontrol })- \\
\text { Percentage of inhibition }(\%)=\frac{(\text { Absorbanceof thesample })}{\text { Theabsorbance of thecontrol }} \times 100
\end{gathered}
$$

Hypotonicity-induced hemolysis

Distinct Katha powder (100-500 $\mu \mathrm{g} / \mathrm{ml})$, reference and control sample were individually mixed among $1 \mathrm{ml}$ of PBS, $2 \mathrm{ml}$ of hypo-saline and $0.5 \mathrm{ml}$ of HRBC suspension. Diclofenac sodium concentration of $100 \mu \mathrm{g} / \mathrm{ml}$ was utilized as a basic reference medicine. Entire assay mixtures were put interior the incubator at about $37^{\circ} \mathrm{C}$ for $30 \mathrm{~min}$ of time and rotated at high speed around $3000 \mathrm{rpm}$. The supernatant liquid was poured off or the hemoglobin content was predicted by a spectrophotometer at $560 \mathrm{~nm}$. All the readings were taken 3 times and percentage hemolysis was predicted by utilizing the formula $[17,18]$

$$
\text { Percentage of inhibition }(\%)=\frac{\begin{array}{c}
(\text { Absorbanceof thecontrol })- \\
\text { (Absorbanceof thesample })
\end{array}}{\text { Absorbance of thecontrol }} \times 100
$$

\section{RESULTS}

\section{Organoleptic evaluation}

The drug appears in pieces of the wavering proportion of 4-4.5 $\mathrm{cm}$ in length and $3.5-4.5 \mathrm{~cm}$ in the breath, yellowish-brown in color, fracture hard with characteristics odor, and astringent in taste as shown in Fig. 2.

\section{Percent yield obtained of Katha after extraction}

The data about Katha content from the heartwood of A. catechu are presented in Table 1. It is apparent from the table that maximum Katha content of $14.64 \%$ was acquired and minimum Katha content is $7.95 \%$, respectively.

\begin{tabular}{|l|l|}
\hline Step I & - Heartwood taken by removal of bark \\
Step II & - Chipping of heartwood \\
Step III & - Autoclave $(10 \%$ hydro-alcoholic solution $)$ \\
Step IV & - Evaporation for concentration of katha \\
Step V & - Filtration, plating, cutting and drying \\
\hline
\end{tabular}

Fig. 1: Demonstrating the step involves in the preparation of Katha 


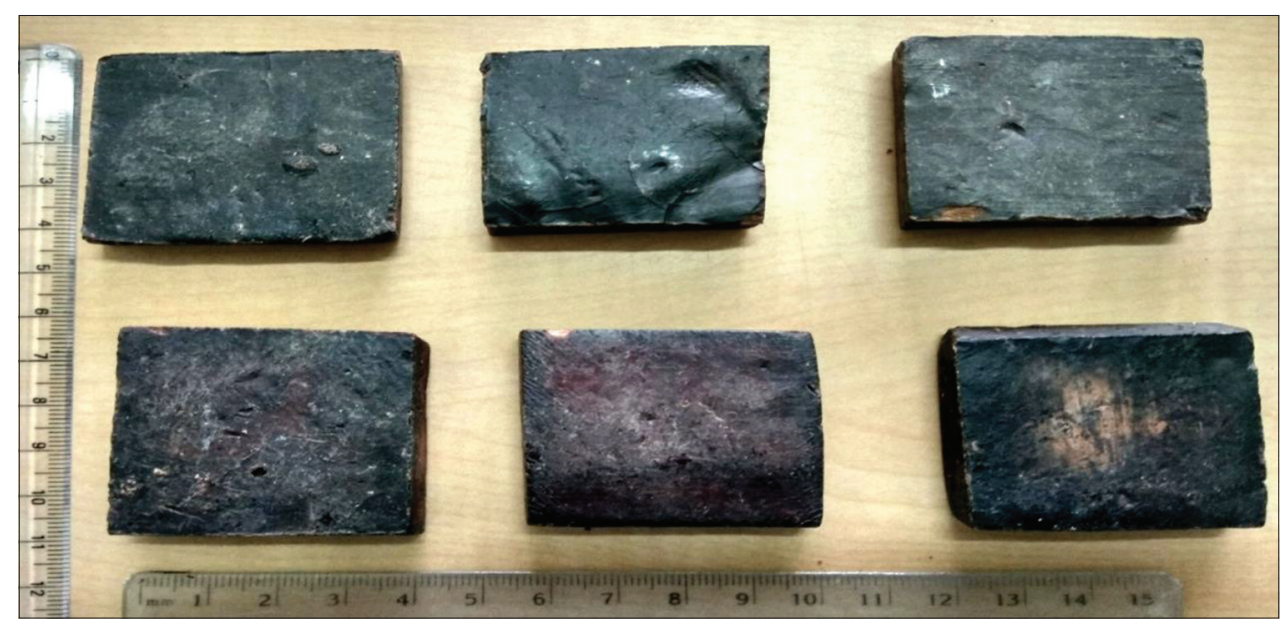

Fig. 2: The organoleptic character of Katha

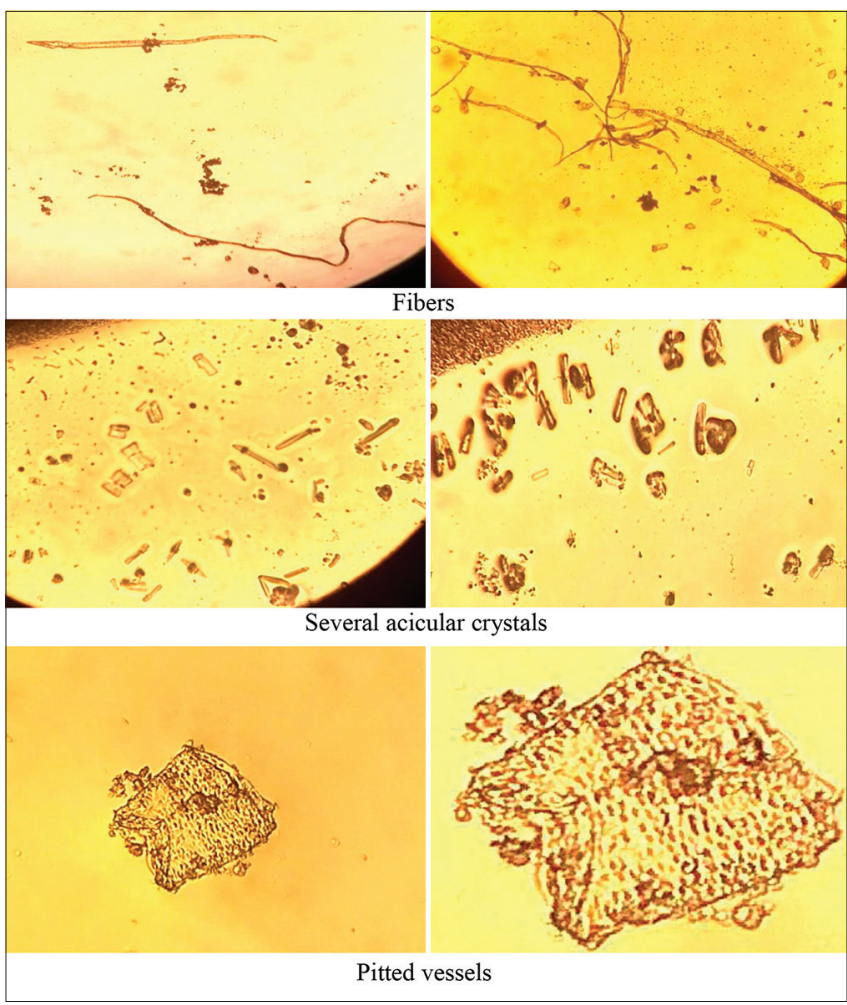

Fig. 3: Powder demonstrate microscopy of Katha

\section{Histochemical investigations and powder microscopy}

The powder demonstrated fragments of acicular crystals, fibers, and bordered pitted vessels scattered thoroughly the powder as shown in Fig. 3.

\section{Fluorescence examinations of Katha powder}

The examinations are designated underneath; the treatment of powdered drugs with distinct chemical reagents reveals the existence of distinct chemical constituents contemporary in the powdered drugs. The Katha powder is inspected in daylight and UV to detect the fluorescent compounds by the documented technique. A fluorescence examination reveals the existence of chemical constituents with fluorescence character in UV light and color change inspected in the visible light. The information is described in Table 2.

\section{Antioxidant potential of the Katha powder}

Antioxidant activities assay (spectrophotometric analysis) by DPPH

The more frequent basis utilization of DPPH assay is straight forward and extremely precise. DPPH is depreciated in the radical form through
Table 1: Percent yield obtained of Katha after extraction

\begin{tabular}{llll}
\hline Trial & Katha extract & \% Yield w/w & Average value w/w \\
\hline Trial I & $\begin{array}{l}10 \% \text { hydroalcoholic } \\
\text { hot distilled water }\end{array}$ & 9.12 & 11.87 \\
Trial II & $\begin{array}{l}10 \% \text { hydroalcoholic } \\
\text { hot distilled water }\end{array}$ & 11.95 & \\
Trial III & $\begin{array}{l}10 \% \text { hydroalcoholic } \\
\text { hot distilled water }\end{array}$ & 14.54 & \\
\hline
\end{tabular}

its strength. The present radical appears a secure absorption maximum at a wavelength of $517 \mathrm{~nm}$ (purple). In the existence of antioxidants, the color turns from purple to yellow. Consequently, the sole apparatus essential for the assay is a UV-visible spectrophotometer. The DPPH free-radical scavenging capabilities of Katha powder at distinct concentrations were estimated and contrast with that of the standard ascorbic acid Table 3. Five distinct working solutions of three Katha powders were utilized having varying concentrations $(0,250,500,750$, and $1000 \mu \mathrm{g} / \mathrm{ml}$ ). Decoloration due to reaction of antioxidant in samples with the stable DPPH free-radical detected by spectrophotometrically. It was perceived that as the concentration of samples enhances, the percentage of free-radical scavenging potential also be enhanced. The antioxidant consequence of botanical products is primarily due to the radical scavenging potential of phenolic compounds such as flavonoids, polyphenols, tannins, and phenolic compounds. When these compounds enhanced in dose, the antioxidant potential enhanced correspondingly in all the samples as shown in Table 3.

Around the entire Katha powder sample samples investigations, the Katha powder appearing in the concentration of $1.0 \mathrm{mg} / \mathrm{ml}$ exhibited the optimum free-radical scavenging potential of $93.16 \%$. Correspondingly, in $0.75 \mathrm{mg} / \mathrm{ml}$ Katha powder exhibited the optimum free radical scavenging potential $(74.72 \%)$. Katha powder at $0.50 \mathrm{mg} / \mathrm{ml}$ had the highest free-radical scavenging potential (40.32\%). $0.25 \mathrm{mg} / \mathrm{ml}$ of Katha powder had optimum free-radical scavenging potential (16.6\%) It was additionally recognized that the entire tested samples appeared lower DPPH radical scavenging potential when collating with the standards. The optimum free-radical scavenging potential was acquired for the ascorbic acid at $1 \mathrm{mg} / \mathrm{ml}$ was raise to be $96.10 \%$. In addition, Fig. 4 is demonstrating that the scavenging percentage of Katha powder was in increasing sequence with the increase in concentration.

\section{NO scavenging technique}

NO radical accused from sodium nitroprusside in aqueous solution at physiological $\mathrm{pH}$ connect among the oxygen to generate nitrite ions which were deliberated by Griess reaction. NO radical accused from nitroprusside at physiological $\mathrm{pH}$ was accomplished to be inhibited by the distinct extract, for example, Katha phytosomes and ascorbic 
Table 2: Data showing Fluorescence analysis of air-dried drug Katha powder with distinct chemicals

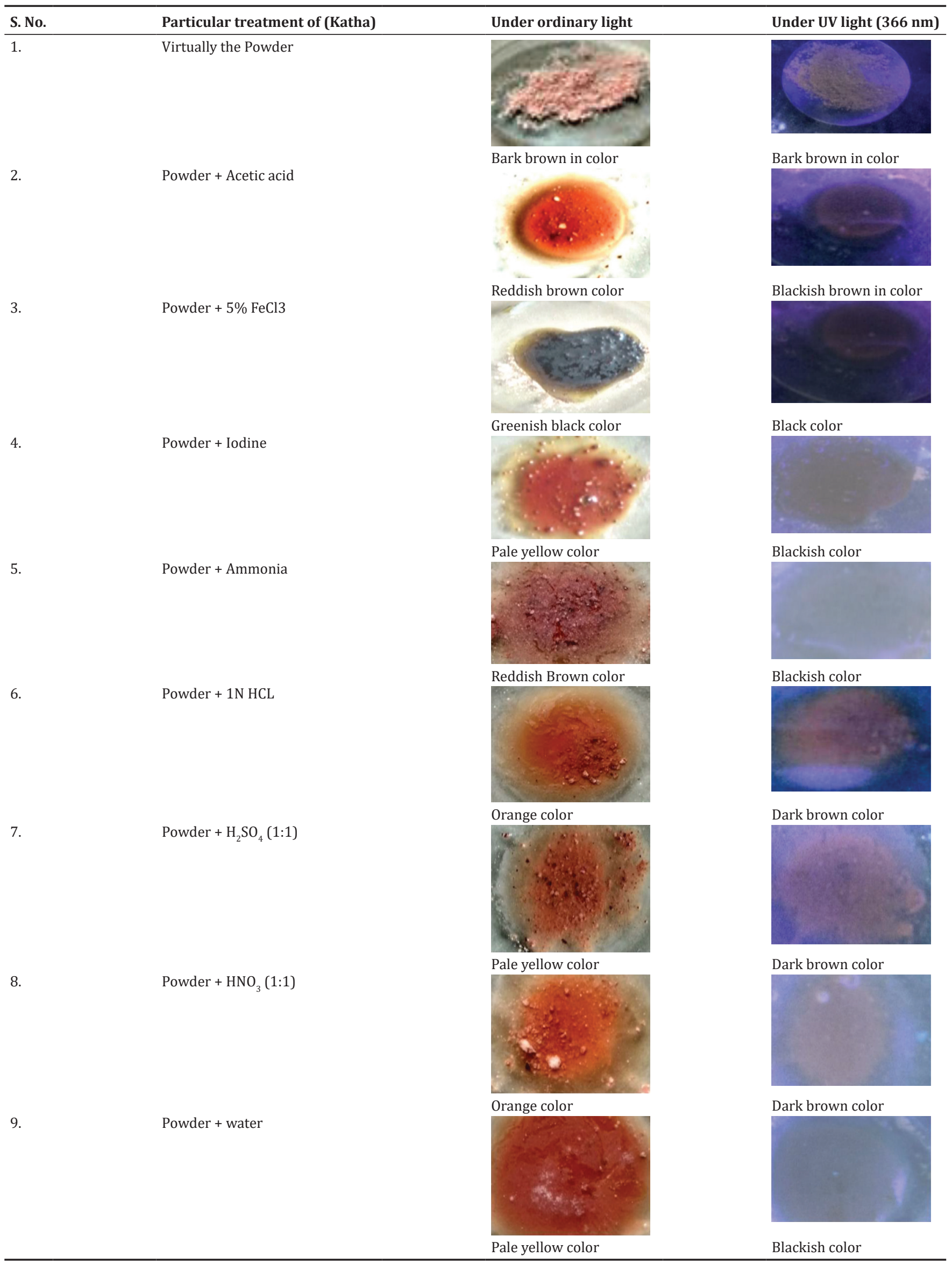


Table 2: (Continued)

\begin{tabular}{lllr}
\hline S. No. & Particular treatment of (Katha) & Under ordinary light & Under UV light (366 nm) \\
\hline 10. & Powder +1 NaOH (water) & & \\
& & Reddish brown color & Black color \\
11. & Powder + methanol & & Pale yellow color \\
\hline
\end{tabular}

Table 3: DPPH free radical scavenging potential in (\%) of Katha powder and ascorbic acid

\begin{tabular}{|c|c|c|c|c|c|c|c|c|c|c|}
\hline \multirow[t]{3}{*}{ Test sample } & \multicolumn{10}{|c|}{ Concentration $(\mathrm{mg} / \mathrm{ml})$} \\
\hline & \multicolumn{2}{|l|}{$\mathbf{0}$} & \multicolumn{2}{|l|}{250} & \multicolumn{2}{|l|}{500} & \multicolumn{2}{|l|}{750} & \multicolumn{2}{|l|}{1000} \\
\hline & $\operatorname{Max}(517)$ & $\%$ & $\operatorname{Max}(517)$ & $\%$ & $\operatorname{Max}(517)$ & $\%$ & $\operatorname{Max}(517)$ & $\%$ & $\operatorname{Max}(517)$ & $\%$ \\
\hline Katha powder & 1.654 & 0 & 1.378 & 16.68 & 0.987 & 40.32 & 0.418 & 74.72 & 0.113 & 93.16 \\
\hline Ascorbic acid & 1.849 & 0 & 1.341 & 27.47 & 0.452 & 75.55 & 0.079 & 95.72 & 0.072 & 96.10 \\
\hline
\end{tabular}

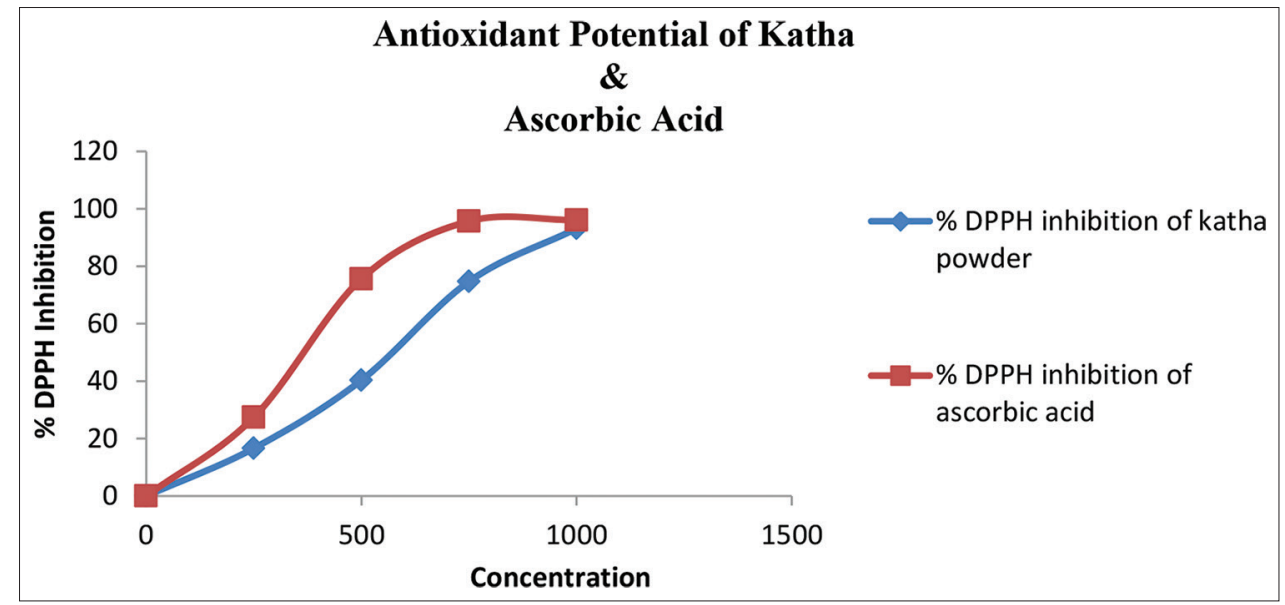

Fig. 4: Demonstrate that the DPPH scavenging percentage of Katha powder and ascorbic acid

acid as manifested in Table 4. Four diverse working solutions of three extracts phytosomes Katha powder and ascorbic acid were utilized having diverse concentrations $(0,250,500,750$, and $1000 \mu \mathrm{g} / \mathrm{ml})$ were utilized. Decoloration due to reaction of antioxidant in samples with the NO free radical was deliberated by spectrophotometrically. It was perceived that when the concentration of samples enhanced, the percentage NO scavenging potential also enhanced as shown in Table 4.

Around the entire Katha powder sample samples investigations, the Katha powder appearing in the concentration of $1.0 \mathrm{mg} / \mathrm{ml}$ exhibited the optimum free-radical scavenging potential of $62.92 \%$. Correspondingly, in $0.75 \mathrm{mg} / \mathrm{ml}$ Katha powder exhibited the optimum free-radical scavenging potential $(56.85 \%)$. Katha powder at $0.50 \mathrm{mg} / \mathrm{ml}$ had the highest free-radical scavenging potential (48.90\%). $0.25 \mathrm{mg} / \mathrm{ml}$ of Katha powder had optimum free-radical scavenging potential (25.54\%) It was additionally recognized that the entire tested samples appeared lower DPPH radical scavenging potential when collating with the standards. The optimum free-radical scavenging potential was acquired for the ascorbic acid at $1 \mathrm{mg} / \mathrm{ml}$ and was raise to be $98.27 \%$. In addition, Fig. 5 is demonstrating that the NO scavenging percentage of Katha powder was in increasing sequence with the increase in concentration.

\section{Anti-inflammatory potential of the Katha powder}

Heat induced hemolysis

Stabilization of the cell membrane of RBCs when asserting with direct controlled heat was investigated to access membrane stabilization potential of diverse drugs concentration in collation to aspirin. The Katha powder was efficacious in inhibiting heat-induced hemolysis at diverse concentrations. This result is demonstrated in graphical form in Table 5.

The results demonstrated that Katha powder at concentrations 400 and $500 \mu \mathrm{g} / \mathrm{ml}$ protects significantly the erythrocyte membrane against lysis induced by heat. Katha powder revealed excellent consequence comparable to standard giving percent inhibition of hemolysis value of $82.62 \%$ as compared to standard $85.57 \%$ at the concentration of $500 \mu \mathrm{g} /$ $\mathrm{ml}$. Table 5 , represent the results obtained for various concentrations of test and standard. The control showed absorbance of (0.305). In addition, Fig. 6 revealed that the percentage inhibition of heat-induced hemolysis of Katha powder was in increasing sequence with the increase in concentration. 


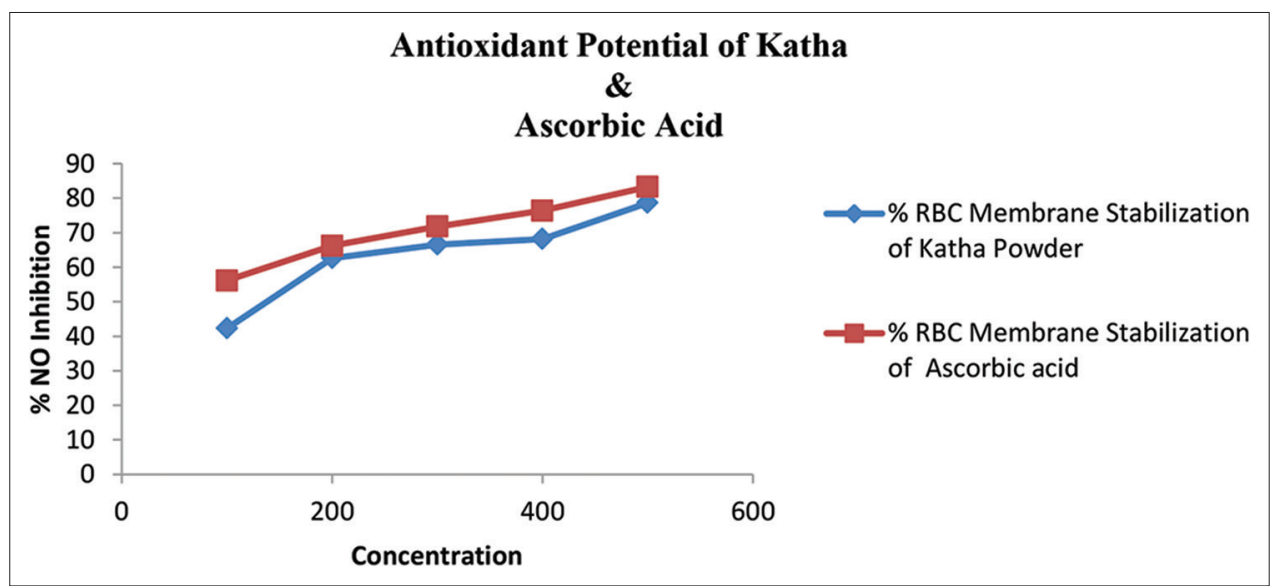

Fig. 5: Demonstrate that the NO scavenging percentage of Katha powder and ascorbic acid

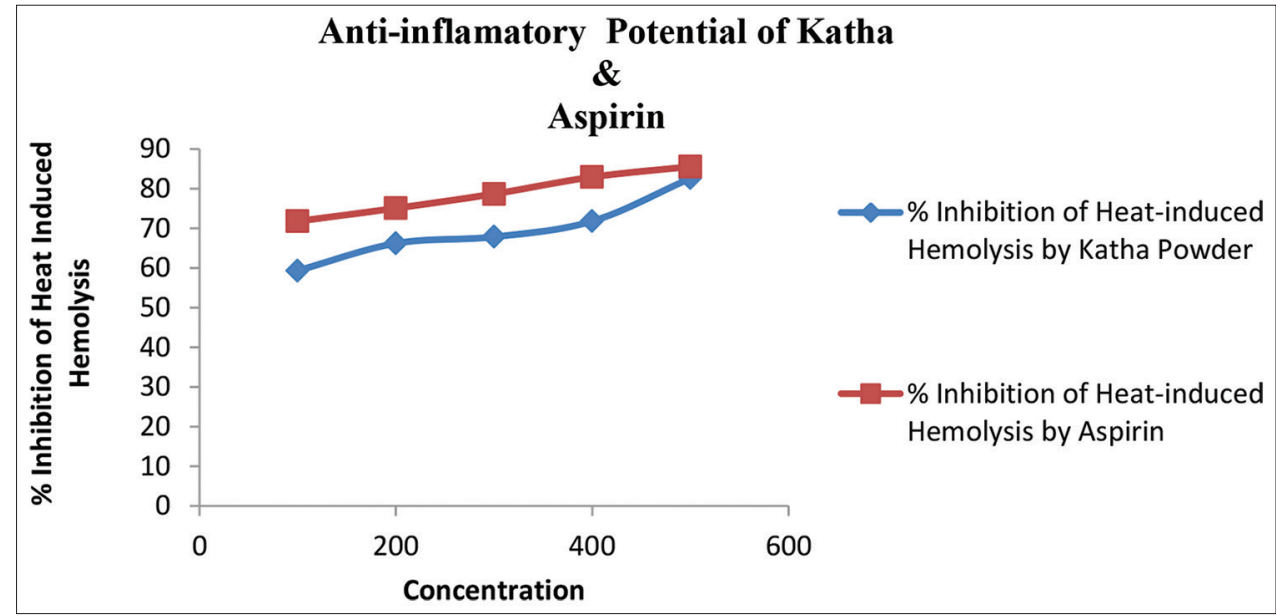

Fig. 6: Demonstrate the heat-induced hemolysis of Katha powder with aspirin as a standard

Table 4: Percentage nitric oxide scavenging activity of Katha powder and ascorbic acid

\begin{tabular}{|c|c|c|c|c|c|c|c|c|c|c|}
\hline \multirow[t]{3}{*}{ Test sample } & \multicolumn{10}{|c|}{ Concentration $(\mathrm{mg} / \mathrm{ml})$} \\
\hline & \multicolumn{2}{|l|}{$\mathbf{0}$} & \multicolumn{2}{|l|}{250} & \multicolumn{2}{|l|}{500} & \multicolumn{2}{|l|}{750} & \multicolumn{2}{|l|}{1000} \\
\hline & $\operatorname{Max}(546)$ & $\%$ & $\operatorname{Max}(546)$ & $\%$ & $\operatorname{Max}(546)$ & $\%$ & $\operatorname{Max}(546)$ & $\%$ & $\operatorname{Max}(546)$ & $\%$ \\
\hline Katha powder & 2.654 & 0 & 1.976 & 25.54 & 1.356 & 48.90 & 1.145 & 56.85 & 0.984 & 62.92 \\
\hline Ascorbic acid & 2.432 & 0 & 1.842 & 24.25 & 0.830 & 65.87 & 0.095 & 96.90 & 0.042 & 98.27 \\
\hline
\end{tabular}

Table 5: Effect of Katha powder on heat-induced hemolysis of erythrocyte

\begin{tabular}{lll}
\hline \multirow{2}{*}{ Concentration $(\boldsymbol{\mu g} / \mathbf{m l})$} & \multicolumn{2}{l}{ Absorbance at $\mathbf{5 6 0} \mathbf{~ n m}$} \\
\cline { 2 - 3 } & Aspirin & Katha powder \\
\hline 500 & 0.044 & 0.053 \\
400 & 0.052 & 0.086 \\
300 & 0.065 & 0.098 \\
200 & 0.076 & 0.103 \\
100 & 0.086 & 0.124 \\
\hline Concentration $(\boldsymbol{\mu g} / \mathbf{m l})$ & \% Inhibition of Heat-induced Hemolysis \\
\hline 500 & 85.57 & 82.62 \\
400 & 82.95 & 71.80 \\
300 & 78.68 & 67.86 \\
200 & 75.08 & 66.22 \\
100 & 71.80 & 59.34 \\
\hline
\end{tabular}

The control showed absorbance at $560 \mathrm{~nm}(0.305)$ used to compare the \% inhibition of heat-induced hemolysis
Hypotonicity induced hemolysis

The RBC membrane stabilization was repeatedly tested by changing related conditions for hemolysis. The consequences manifested that Katha powder of at concentration range of $200-500 \mu \mathrm{g} / \mathrm{ml}$ shield, represented below in Table 6. Diclofenac sodium (100-500 $\mu \mathrm{g} / \mathrm{ml})$ provided remarkable protection across the damaging ramification of hypotonic solution. Through the concentration of $500 \mu \mathrm{g} / \mathrm{ml}$, Katha powder manifested a maximum of $69.83,64.91$, and 67.54 protection, whereas Diclofenac sodium $(500 \mu \mathrm{g} / \mathrm{ml}$ ) revealed $83.27 \%$ inhibition of RBC hemolysis when correlating with control. The control showed absorbance of (0.305). In addition, Fig. 7 is demonstrating that the $\%$ RBC Membrane Stabilization of Katha powder was in increasing sequence with the increase in concentration.

\section{DISCUSSION}

Katha obtained by boiling the heartwood of $A$. catechu with a $10 \%$ hydroalcoholic solution increased the percentage yield value up to $12 \% \mathrm{w} / \mathrm{w}$. Conventionally, the aqueous extract is used for the production 


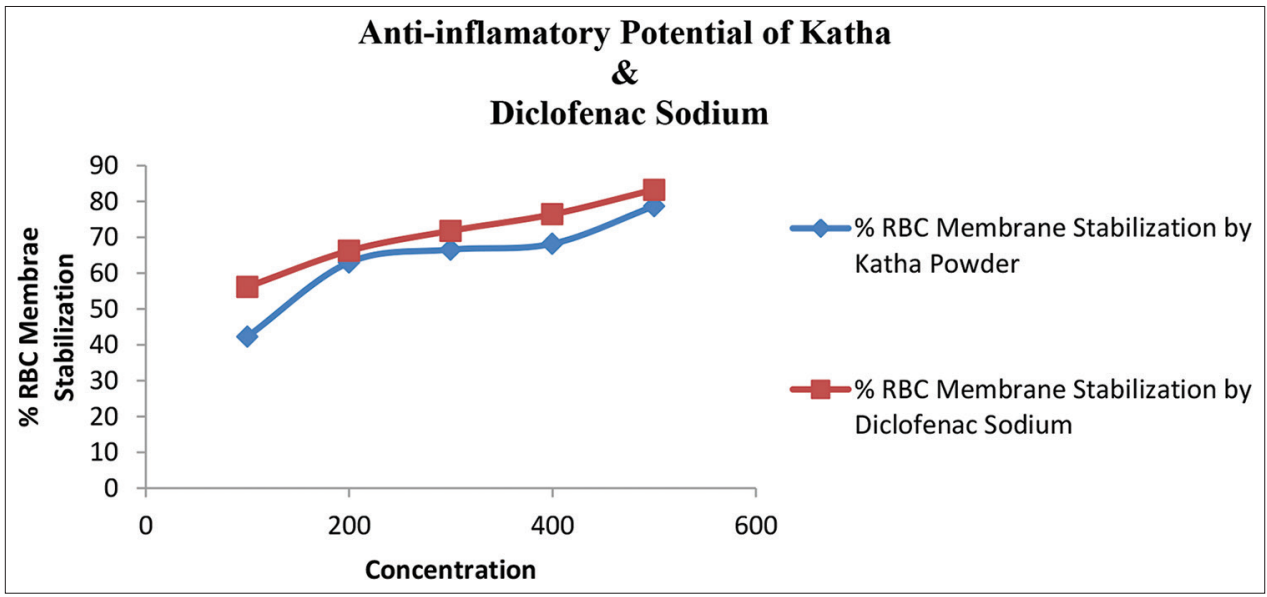

Fig. 7: Demonstrating the hypo-tonicity induced hemolysis of, Katha powder with diclofenac sodium as a standard

Table 6: Effect of Katha powder on hypo-tonicity induced hemolysis of erythrocyte

\begin{tabular}{lll}
\hline Concentration $(\boldsymbol{\mu g} / \mathbf{m l})$ & \multicolumn{2}{l}{ Absorbance at $\mathbf{5 6 0} \mathbf{~ n m}$} \\
\cline { 2 - 3 } & Diclofenac sodium & Katha powder \\
\hline 500 & 0.051 & 0.065 \\
400 & 0.072 & 0.097 \\
300 & 0.086 & 0.102 \\
200 & 0.103 & 0.113 \\
100 & 0.152 & 0.176 \\
\hline Concentration $(\boldsymbol{\mu g} / \mathbf{m l})$ & \% RBC membrane stabilization \\
\hline 500 & 83.27 & 78.68 \\
400 & 76.39 & 68.19 \\
300 & 71.80 & 66.55 \\
200 & 66.22 & 62.95 \\
100 & 56.16 & 42.29 \\
\hline
\end{tabular}

The control showed absorbance at $560 \mathrm{~nm} \mathrm{(0.305)}$ used to compare the \% RBC membrane stabilization

of the Katha from the heartwood having yield value 6-7\%. In this study, the new approach can be accelerated the yield value of the Katha. The powder microscopy of the Katha powder is to be demonstrated fragments of acicular crystals, fibers, and bordered pitted vessels it is good diagnostic character of the Katha. When these compounds enhanced in dose, the antioxidant potential enhanced correspondingly in all the samples. It is to be observed that the Katha powder is to show comparable antioxidant potential in the comparison of the ascorbic acid. This study is to be suggested that the drug is to possess excellent antioxidant potential. Further, the Katha in vitro anti-inflammatory study is to be suggested that the Katha powder is to possess good action against the inflammatory disorder in the body. This study is to be recommended that the Katha powder is to be good antioxidant and anti-inflammatory action to cure the various body disorders instead of using the $A$. catechu heartwood.

\section{CONCLUSION}

This study is to be presented us that the drug yield value can be enhanced using the extraction of such type of the modified method. Since the yield value with the traditional method is to be only $5 \%$ but using the $10 \%$ alcoholic solution it can be increased up to $10-12 \%$. Katha as traditional methods of extraction along with the high yields value it also has shown the high content of the tannin, flavonoids, and phenolic compounds. DPPH and NO radical scavenging approaches show the good antioxidant potential of the Katha powder. Further, the heat-induced, as well as hypo-tonicity induced approach, demonstrates that the drug is having a good anti-inflammatory activity in the human body. The result of the investigation is to be suggested that the Katha powder is rich in the phenolic compound and the experimentation study shows that the drug is to possess a good antioxidant as well as anti-inflammatory property.

\section{ACKNOWLEDGMENTS}

The authors extend thanks to Dr. Athar Javed and Mr. Tarapati Rana, Faculty of Pharmacy, Government Pharmacy College Seraj, Mandi (H.P.) for his technical support to carry out this research study.

\section{CONFLICT OF INTEREST}

The authors declare no conflict of interest, financial, or otherwise.

\section{ETHICS APPROVAL AND CONSENT TO PARTICIPATE}

Not applicable.

\section{HUMAN AND ANIMAL RIGHTS}

No Animals/Humans were used for studies that are based on this research.

\section{CONSENT FOR PUBLICATION}

Not applicable.

\section{AUTHOR FUNDING}

Not applicable.

\section{REFERENCES}

1. Hazra B, Sarkar R, Biswas S, Mandal N. The antioxidant, iron chelating and DNA protective properties of $70 \%$ methanolic extract of Katha (Heartwood extract of Acacia catechu). J Complement Integr Med 2010;7:1-20

2. Sharma, P. Investigation on pharmacognosy of Katha powder as well as its in vitro cytotoxic activity. Asian J Pharm Clin Res 2021;14:133-40.

3. Zahin M, Aqil F, Ahmad I. The in vitro antioxidant activity and total phenolic content of four Indian medicinal plants. Int J Pharm Pharm Sci 2009; 1: 88-95.

4. Mokhtar MA, Ahmad MA, Nizami Q, Ahmad FJ, Rahman MM. The wound-healing effect of an Unani formulation Marham-e-Ral in albino rats. Int J Adv Pharm Med Bioallied Sci 2014;2:20-4.

5. Jayasekhar P, Mohanan PV, Rathinam K. Hepatoprotective activity of ethyl acetate extract of Acacia catechu. Indian J Pharmacol 1997;29:426-8.

6. Sharma P. Investigation on photodecomposition of standardised ethyl acetate fraction of Katha. Pharmacogn J 2020;12:815-20.

7. Karnik MG, Sharma OP, Dobhal NP. Pilot plant production of Katha and cutch from Khair tree Acacia catechu Willd. Indian Forester 
1965;91:778-80.

8. Singh KN, Lal, B. Notes on traditional uses of Khair (Acacia catechu Willd.) by inhabitants of Shivalik range in Western Himalaya. Ethnobot Leaf 2006;10:109-12.

9. Jain RA, Patni VI, Arora DK. Isolation and identification of flavonoid "quercetin" from Acacia catechu (Lf) Willd-A Katha yielding plant. J Phytol Res 2007;20:43-5.

10. Sharma, RP. Yield tables of Acacia catechu (Khair) (plantation origin) for various levels of stocking. Indian Forester 1981;107:551-62.

11. Selvam AB, Bandyopadhyay S. Fluorescence analysis on the roots of Rauwolfia serpentina (L.) Benth. Ex kurz under UV radiation. Anc Sci Life 2005;24:164-7.

12. Prakash NK, Ranjith M, Sripriya N, Lakshmi RP, Deepa S, Bhuvaneswari S. Antioxidant, free radical scavenging activity and GCMS studies on Pedilanthus tithymaloides (1.) Poit. Int J Pharm Pharm Sci 2014;6:284-7.

13. Kedare SB, Singh RP. Genesis and development of DPPH method of antioxidant assay. J Food Sci Technol 2011;48:412-22.
14. Al-Henhena N, Ying RP, Ismail S, Najm W, Khalifa SA, El-Seedi H, et al. Chemopreventive efficacy of Andrographis paniculata on azoxymethane-induced aberrant colon crypt foci in vivo. PLoS One 2014;9:1-12

15. Alhminghlui K, Jagetia GC. Evaluation of the free-radical scavenging and antioxidant activities of Chilauni, Schima wallichii Korth in vitro. Future Sci OA 2018;4:FSO272.

16. Ho PJ, Sung JJ, Cheon KK, Tae HJ. Anti-inflammatory effect of Centella asiatica phytosome in a mouse model of phthalic anhydride induced atopic dermatitis. Phytomedicine 2018;43:110-9.

17. Saleem TM, Azeem A, Dilip C, Sankar C, Prasanth N, Duraisami R. Anti-inflammatory activity of the leaf extracts of Gendarussa vulgaris Nees. Asian Pac J Trop Biomed 2011;1:147-9.

18. Ranasinghe P, Ranasinghe P, Kaushalya WP, Abeysekera M, Premakumara GA, Perera YS, et al. In vitro erythrocyte membrane stabilization properties of Carica papaya L. leaf extracts. Pharmacogn Res 2012;4:196-202. 